\title{
Development of nanolubricant automotive air conditioning (AAC) test rig
}

\author{
A.A.M. Redhwan ${ }^{1,3,{ }^{*}}$, W.H. Azmi ${ }^{1,2}$, M.Z. Sharif ${ }^{1}$, Ftwi Y. Hagos ${ }^{1}$ \\ ${ }^{1}$ Faculty of Mechanical Engineering, Universiti Malaysia Pahang (UMP), 26600 Pekan, Pahang, \\ Malaysia. \\ ${ }^{2}$ Automotive Engineering Centre, Universiti Malaysia Pahang, 26600 Pekan, Pahang, Malaysia. \\ ${ }^{3}$ Faculty of Manufacturing Engineering Technology, TATI University College, 24000 Kemaman, \\ Terengganu, Malaysia.
}

\begin{abstract}
Nanolubricant been introduced in compressor might improve the performance of automotive air conditioning system. Prior testing of the nanolubricant enhancement performance, an automotive air conditioning (AAC) system test rig base on compact car has to be developed; therefore this paper presented the development process of AAC test rig. There are 15 thermocouples, 2 pressure gauges and power analyzer were assembled on the system in order to analyse its performance. The experiment was conducted with four different charged of refrigerant. The charging was based on initial weight charged. At each quantity of refrigerant charge, performance of the AAC system was evaluated by determining three important parameters which is cooling capacity, compressor work and coefficient of performance (COP). The maximum average COP is achieved at 900 RPM is 7.07. The average and maximum COP enhancement of 7.07 $\%$ and $13.34 \%$ were achieved by applying $\mathrm{SiO}_{2}$ nanolubricant inside the compressor.
\end{abstract}

\section{Introduction}

The automotive air-conditioning (AAC) is becoming a need for thermal comfort in passenger's cabin especially in equatorial countries experiencing hot and humid climate throughout the year. The AAC is expected able to remove the heat produced in the passenger compartments of the cars as quickly as possible under any given environmental condition. In automotive sectors, air conditioning compressor is the single largest auxiliary load on an automotive engine [1]. Extra load used by the AAC system implies less efficiency, causing more fuel consumption and more greenhouse gas discharges. A study in 2001 shows ACC utilization decreases mileage around $20 \%$ and builds discharged of nitrogen oxides (NOx) by $80 \%$ and carbon dioxide (CO) by $70 \%$ [1] [2].

One of the best ways to improve the efficiency of AAC is by implementing nanofluids in the refrigeration system; by replacing conventional lubricant with nanolubricant. Adding nanoparticles to the base liquids can altogether increase their transport properties and the efficiency of the system, regardless of the possibility that the impact on pressure must be

\footnotetext{
*Corresponding author: redhwan323@gmail.com
} 
deliberately evaluated. In addition, nanolubricants can enhance their tribological properties (lubricity, against wear properties, high pressure condition) with clear advantages for the compressors.

The uses of nanoparticle in refrigerant/lubricant mixture in improving coefficient performance/cooling capacity in refrigeration system were done by few researchers [4-10]. For example, $\mathrm{Bi}$, et al. [3] conducted experiment of mineral oil with $\mathrm{TiO}_{2}$ nanoparticles mixtures as lubricant in domestic refrigerator. They concluded that $26.1 \%$ less energy consumption was achievable. The same authors also conducted experimental work for performance of a domestic refrigerator using $\mathrm{TiO}_{2} / \mathrm{R} 600$ a nanorefrigerant as working fluid. The performance of refrigerator showed $9.6 \%$ less energy used [4]. Wang, et al. [5] mixed $\mathrm{NiFe}_{2} \mathrm{O}_{4}$ in mineral-based nanorefrigeration oil (MNRO). The outcome of the test showed that cooling/heating EER of the RAC were increased by $6 \%$. Jwo, et al. [6] dispersed $\mathrm{Al}_{2} \mathrm{O}_{3}$ nanoparticles in polyester lubricants. They found that the power consumption decreased by $2.4 \%$ and the COP was enhanced up to $4.4 \%$. Subramani and Prakash [7] dispersed $\mathrm{Al}_{2} \mathrm{O}_{3}$ in $\mathrm{MO}$. It is observed that by using $\mathrm{Al}_{2} \mathrm{O}_{3} / \mathrm{R} 134 \mathrm{a} / \mathrm{MO}$ nanorefrigerant, the power consumption was reduced by $25 \%$ and up to 1.53 enhancement factor in the evaporator was attained. Sabareesh, et al. [8] were experimenting the effect of dispersing low concentration of $\mathrm{TiO}_{2}$ nanoparticles in the mineral oil based lubricant. This experimental results showed that the enhancement in COP and average heat transfer rate were $17 \%$ and $3.6 \%$ respectively. Kumar and Elansezhian [9] dispersed $\mathrm{Al}_{2} \mathrm{O}_{3}$ nanoparticle in polyalkylene glycol (PAG) oil used in $\mathrm{R} 134 \mathrm{a}$ vapor compression refrigeration system. When compared to pure $\mathrm{R} 134 \mathrm{a} / \mathrm{PAG}$ mixture, 0.2 vol. \% concentration $\mathrm{Al}_{2} \mathrm{O}_{3} / \mathrm{R} 134 \mathrm{a} / \mathrm{PAG}$ nanorefrigerant showing better performance of the refrigeration system with $10.32 \%$ less energy used. Even though many research works were done on the refrigeration system, none of them are using automotive air conditioning (AAC) as the test rig.

Hence in this work, an AAC system test bench was developed and built in according to SAE International standard, J2765 OCT 2008. AAC system of a compact car consists of basics refrigeration system components was selected. The Coefficient of Performance (COP) test was conducted to compare the performance of the AAC with and without nanolubricant providing the basic data for the application of the nanoparticles in the AAC system.

\section{Methodology}

The experimental set-up was made up of original components from the air conditioning system of a compact car, is arranged in such a way to imitate those in the actual vehicle. The experimental bench setup was made of AAC system from a compact car, electrical motor and inverter frequency controller, water bath for evaporator, piping system and various measurement instruments as shown in Figure 1. The components used are listed in Table 1. 


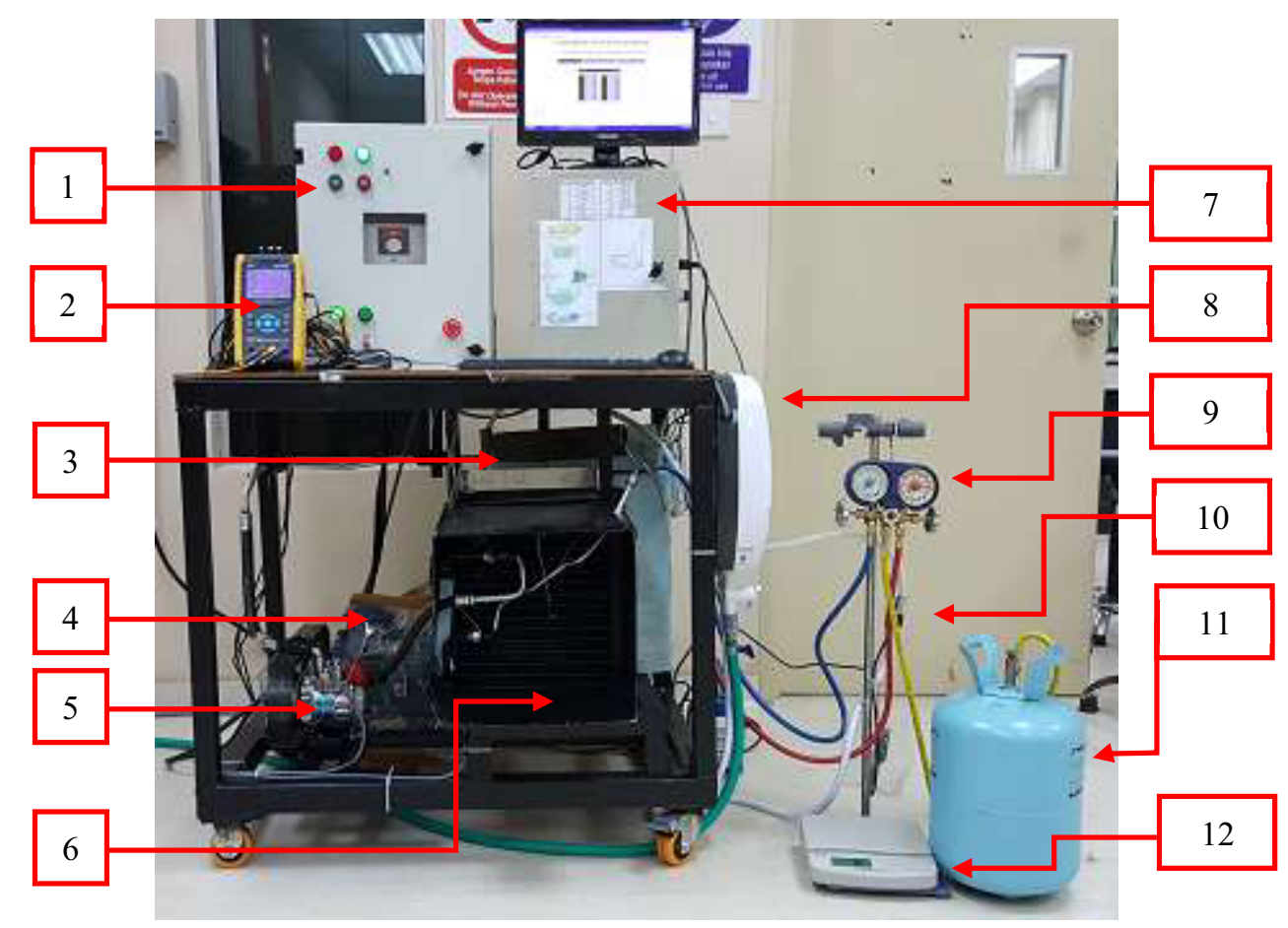

Fig. 1. The setup of AAC Test rig.

Table 1. List of component used in AAC Test rig

\begin{tabular}{|c|c|c|c|}
\hline No. & Description & No. & Description \\
\hline 1 & Frequency Inverter Controller & 7 & Data Logger Module \\
\hline 2 & Power Analyzer & 8 & Water Heater \\
\hline 3 & Evaporator (inside Water bath) & 9 & Pressure Gauge \\
\hline 4 & Three phase induction motor & 10 & Flow Transducer \\
\hline 5 & Compressor & 11 & R134a gas \\
\hline 6 & Condenser & 12 & Weight Scale \\
\hline
\end{tabular}

The AAC system used in the present study was from a Kancil SD specification. The compressor used is a SWJ -7B08 Sanden compressor and ran with R134a as refrigerant. The compressor and its AAC system is been lubricated by Polyalkylene Glycol (PAG). The main components of AAC system were compressor, condenser, evaporator and expansion valve. The compressor pulley is driven by a $2.2 \mathrm{~kW}, 3$-phase electrical motor acted upon by a frequency inverter in order to control and vary the rotational speed. The speed used in this study is varies between 900 and 2100 revolution per minute (RPM) by varying the motor's frequency. For ease and consistent evaporator temperature measurement reading, the evaporator is been immersed in water by implementing water bath system. The calculation of Coefficient of performance (COP) by immersing the evaporator in water bath is done according to ASHRAE 41.9-2000. The water bath system was equip with a fully thermal insulated tank, a flow transducer, 3-ways inlet and outlet pipes for achieving homogenous water temperature in the water bath and a water heater that regulate the water inlet temperature and flow rate. The AAC system was appropriately equip with temperature sensors, digital power analyzer and pressure gauges. The temperatures at 15 points were assessed using calibrated K-type thermocouples following to ANSI/ASHRAE Standard, 
1986. Out of fifteen (15) thermocouples installed, eight (8) were installed at along of the AAC system pipeline at specific location at inlet and outlet of each main component. The calibration of thermocouple were done in contra with the Standard Platinum Resistance Thermometer (SPRT) as performed by [10] and [11]. Table 2 shows the two sets of data with different conditions of water used during calibration. The thermocouple used was of Ktype, $0.3 \mathrm{~mm}$ diameter and aimed for temperature span between -40 to $375^{\circ} \mathrm{C}$ with $\pm 1.5^{\circ} \mathrm{C}$ tolerance.

Table 2. Calibration data for thermocouple points and its location.

\begin{tabular}{|c|c|c|c|}
\hline \multirow{2}{*}{$\begin{array}{c}\text { Thermocouple } \\
\text { Type/ No. }\end{array}$} & \multicolumn{2}{|c|}{ Temperature Measurement $\left({ }^{\circ} \mathrm{C}\right)$} & \multirow{2}{*}{$\begin{array}{l}\text { Locations/ } \\
\text { Remarks }\end{array}$} \\
\hline & Freezing & Boiling & \\
\hline Platinum & 0.0 & 100.0 & Calibration set \\
\hline 1 & 0.1 & 100.1 & Comp $_{\text {in }}$ \\
\hline 2 & 0.2 & 100.2 & Comp out \\
\hline 3 & 0.0 & 100.1 & Cond $_{\text {in }}$ \\
\hline 4 & 0.0 & 100.0 & Cond $_{\text {out }}$ \\
\hline 5 & -0.1 & 100.0 & Exp. valve in $_{\text {n }}$ \\
\hline 6 & 0.0 & 100.2 & Exp valve $_{\text {out }}$ \\
\hline 7 & 0.1 & 100.2 & Evap $_{\text {in }}$ \\
\hline 8 & -0.1 & 100.0 & Evap $_{\text {out }}$ \\
\hline 9 & -0.1 & 99.8 & Water bath in $_{\text {in }}$ \\
\hline 10 & 0.1 & 100.0 & Water bath out1 \\
\hline 11 & 0.1 & 100.1 & Water bath out 2 \\
\hline 12 & 0.0 & 100.0 & Water bath out3 \\
\hline 13 & 0.0 & 100.1 & Air cond ${ }_{\text {in }}$ \\
\hline 14 & 0.1 & 100.2 & Air cond ${ }_{\text {out }}$ \\
\hline 15 & -0.1 & 99.7 & Amb. Temp \\
\hline
\end{tabular}

The temperatures and water flow rate measurement were recorded and observed via a data logger. Pressure gauges used in this experiment was of bourdon tube type gauges and was calibrated. Evaporator and condenser pressure were assessed through calibrated pressure gauges. The pressure data were tracked manually. The power consumption of the AAC system is measured by using power analyzer. As stated earlier, all measurement devices were calibrated and the measurement devices were found to be working accordingly. The initial refrigerant charge is been weighted in grams. The initial charged is ranged between 100 to 130 grams. Last but not least, the temperature and humidity of the room where the test rig is allocated is been monitored and controlled between 24.5 to $25.5^{\circ} \mathrm{C}$ and at 45 to 65 $\%$ respectively. A schematic diagram of the AAC system test rig is depicted in Figure 2.

Temperatures and pressures assessed at the specific points are vital associated to cooling capacity, compressor work and COP. The measured temperature and pressure were used to ascertain the specific point of enthalpy value. In this experiment, five sets of temperatures and pressures data were collected for five different refrigerant initial charges. Each set of data was repeated 3 times on different days to ensure its reliability. The temperature and pressure were assessed for 10 minutes, after the AAC was in steady-state condition as suggested by SAE International standard, J2765 OCT 2008. The enthalphy at point of interest was determined by assessing the temperature and pressure at that point. The final average enthalpy value then was acquired from the 3 repeated experiments. The calculated enthalpy value then been used in determining the cooling capacity $\left(\mathrm{Q}_{\mathrm{L}}\right)$, the compressor work $\left(\mathrm{W}_{\text {in }}\right)$ and Coefficient of performance (COP) by using Eqs. (1) - (3) as shown respectively:- 


$$
\begin{aligned}
& Q_{L}=h_{1}-h_{4} \\
& W_{i n}=h_{2}-h_{1} \\
& C O P=\frac{Q_{L}}{W_{i n}}=\frac{h_{1}-h_{4}}{h_{2}-h_{1}}
\end{aligned}
$$

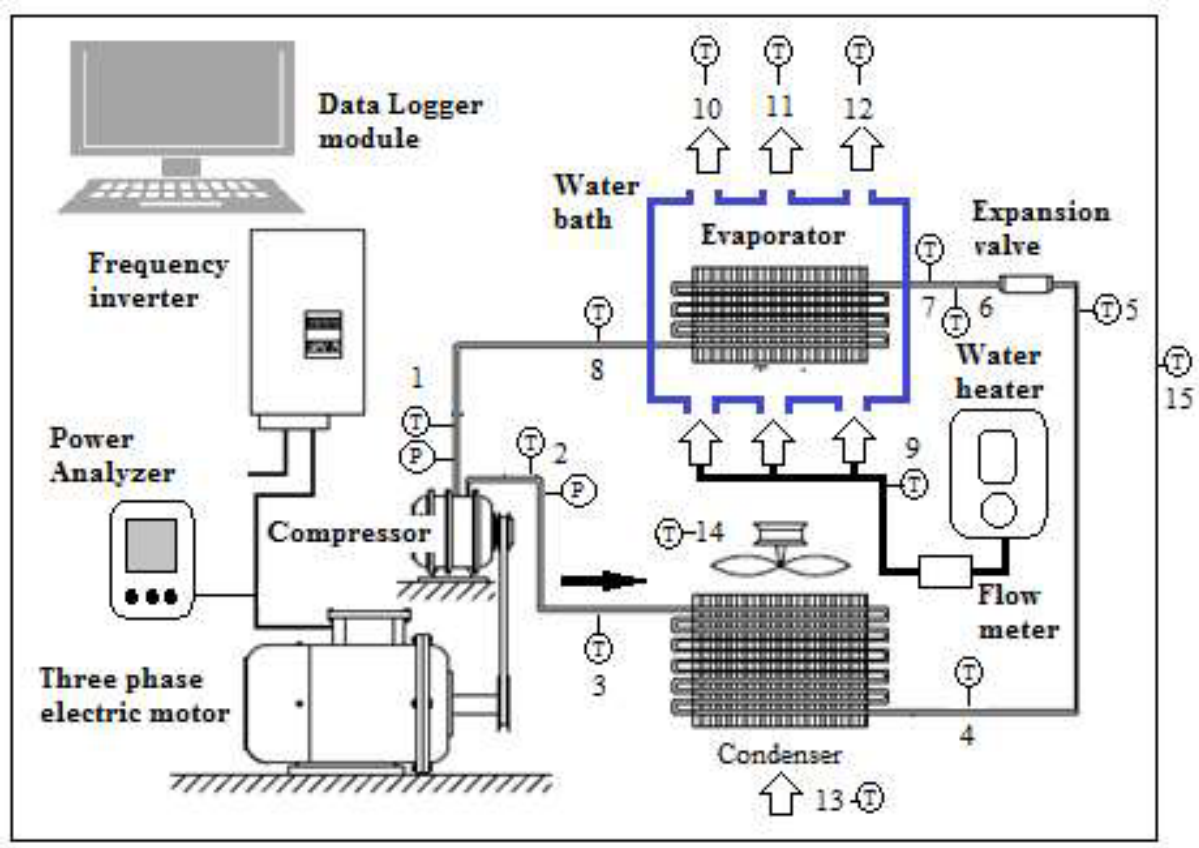

Fig. 2. The schematic diagram of AAC test rig.

\section{Results and discussion}

Figure 3 depicts the cooling capacity per unit mass for the test rig in the function of initial refrigerant charged for three different RPM. The cooling capacity is increased by increasing the initial charge. The cooling capacity also increases by increasing the speed of the compressor. The result data is agreed with [12]. It is observed that the cooling capacity result is increasing almost linearly with refrigerant charged. Kim et al. [13] observed a similar pattern and concluded that specific cooling capacity increased linearly with the amount charged. At lower refrigerant charge, the cooling capacity is low and it may due to the twophase refrigerant flow from condenser to the expansion valve. Figure 4 depicts the compressor work per unit mass in the function of initial refrigerant charged. The compressor work is increasing by increasing the compressor speed. The higher the speed of the compressor, the harder work needs to be done by the compressor, reducing its efficiency. 


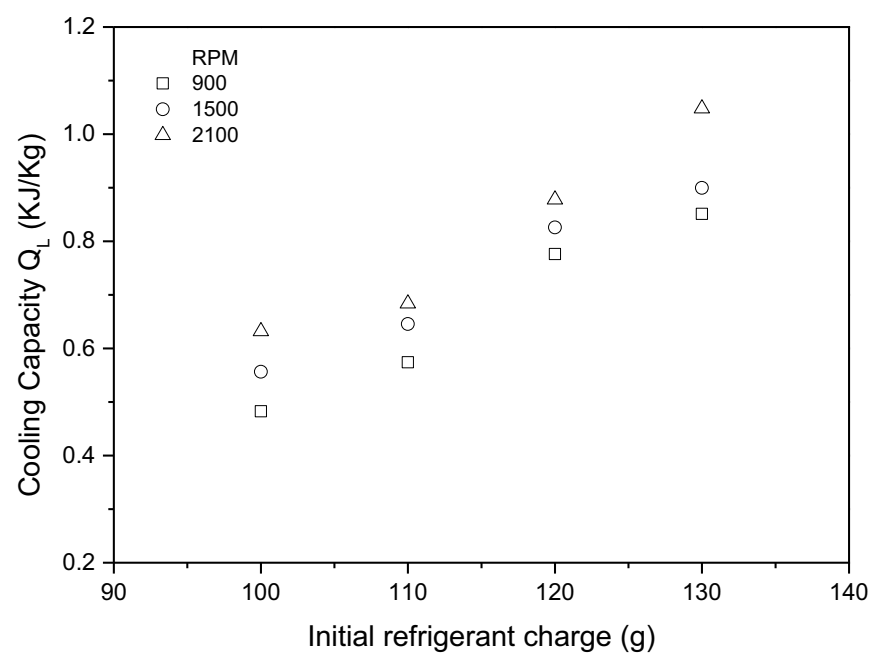

Fig. 3. Cooling capacity per unit mass in the function of initial refrigerant charge.

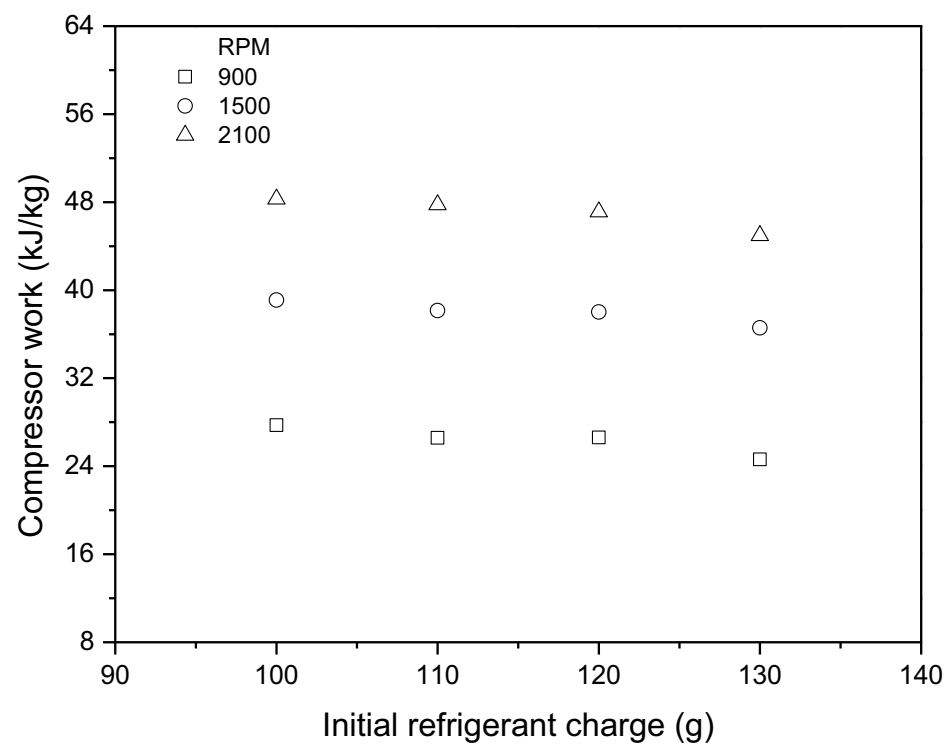

Fig. 4. Compressor work per unit mass in the function of initial refrigerant charge.

While Figure 5 shows the coefficient of performance (COP) of the test rig in the function of initial refrigerant charge. The COP is determined by using equation 3 , where cooling capacity and compressor work play important roles in deciding the efficiency. From the graph, it shows that the COP is increased with the increase of refrigerant initial charge. This is due to the increasing of the cooling capacity (QL) and decreasing in the compressor work with the increasing of initial charge, hence the COP is increasing. On the other hand, the COP is decreased with the increasing of the compressor speed. The experimental results here reflect that the compressor work plays more dominant roles in deciding the efficiency of the 
test rig. As mention earlier, the higher the compressor speed, the higher work has to be done by the compressor and it gives negative effect to the compressor efficiency. The highest average COP is recorded at $900 \mathrm{RPM}$ with the average value of 7.17. COP of the $\mathrm{SiO}_{2}$ nanolubricant also has been determined and plotted in Figure 5. The value is then compared with the pure lubricant as a preliminary discussion. When $0.3 \%$ volume concentration $\mathrm{PAG} / \mathrm{SiO}_{2}$ is placed inside the compressor, the compressor work is slightly lower than an AAC with pure PAG. This is a positive result because less compressor work leads to a higher coefficient of performance (COP). The average enhancement of the COP is $7.07 \%$ and maximum COP achieved is $13.34 \%$.

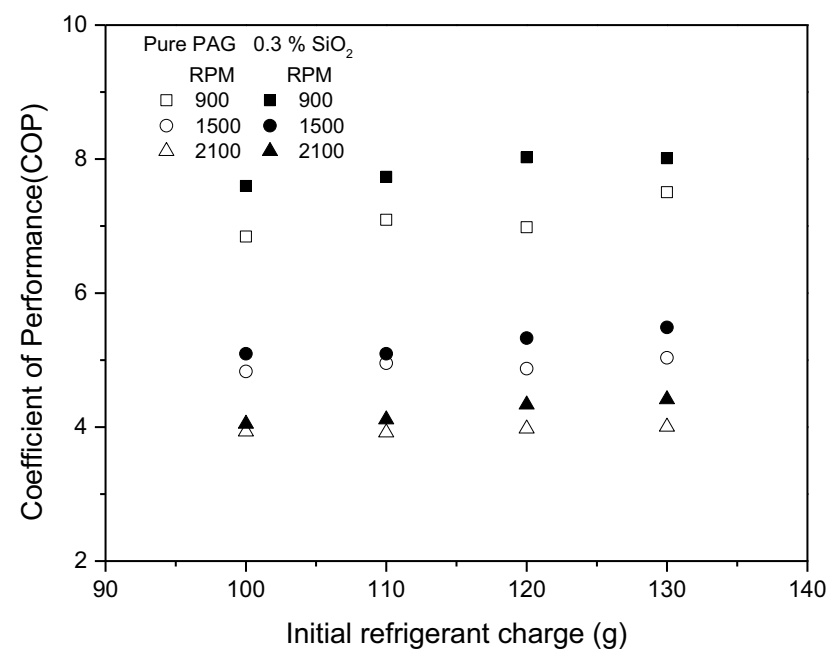

Fig. 5. Coefficient performance of the test rig in the function of initial charge.

\section{Conclusions}

Development of the AAC test rig has been explained thoroughly. The location and calibration of the thermocouple also have been discussed. Cooling capacity and compressor work are plotted against refrigerant initial charge before the coefficient of the performance was plotted. From experimental findings, maximum average COP of the test rig is 7.07 is recorded. The average and maximum COP enhancement of $7.07 \%$ and $13.34 \%$ are achieved by implementing $\mathrm{SiO}_{2}$ nanolubricant.

The authors are grateful to the Universiti Malaysia Pahang (UMP) and Automotive Engineering Centre (AEC) for financial supports given under RDU1403153 and RDU151411 (RAGS/1/2015/TK0/UMP/03/2).

\section{References}

1. J. P. Rugh, T. J. Hendricks, and K. Koram, "Effect of solar reflective glazing on Ford Explorer climate control, fuel economy, and emissions," in Proceedings of the International Body Engineering Conference, 2001. 
2. O. Bevilacqua, "Effect of air conditioning on regulated emissions for in-use vehicles," Clean Air Vehicle Technology Center, Oakland, CA, Phase I Final Report Prepared for Coordinating Research Council, Inc., Atlanta, GA, CRC Project E-37, 1999.

3. S.-s. Bi, L. Shi, and L.-1. Zhang, "Application of nanoparticles in domestic refrigerators," Applied Thermal Engineering, vol. 28, pp. 1834-1843, 2008.

4. S. Bi, K. Guo, Z. Liu, and J. Wu, "Performance of a domestic refrigerator using $\mathrm{TiO}_{2}-$ R600a nano-refrigerant as working fluid," Energy Conversion and Management, vol. 52, pp. 733-737, 2011.

5. R. Wang, Q. Wu, and $\mathrm{Y}$. Wu, "Use of nanoparticles to make mineral oil lubricants feasible for use in a residential air conditioner employing hydro-fluorocarbons refrigerants," Energy and Buildings, vol. 42, pp. 2111-2117, 2010.

6. C. S. Jwo, L. Y. Jeng, T. P. Teng, and H. Chang, "Effects of nanolubricant on performance of hydrocarbon refrigerant system," Journal of Vacuum Science \& Technology B, vol. 27, pp. 1473-1477, 2009.

7. N. Subramani and M. Prakash, "Experimental studies on a vapour compression system using nanorefrigerants," International Journal of Engineering, Science and Technology, vol. 3, pp. 95-102, 2011.

8. R. K. Sabareesh, N. Gobinath, V. Sajith, S. Das, and C. Sobhan, "Application of $\mathrm{TiO}_{2}$ nanoparticles as a lubricant-additive for vapor compression refrigeration systems-An experimental investigation," International Journal of Refrigeration, vol. 35, pp. 19891996, 2012.

9. D. S. Kumar and R. Elansezhian, "Experimental study on $\mathrm{Al}_{2} \mathrm{O}_{3}-\mathrm{R} 134 \mathrm{a}$ nano refrigerant in refrigeration system," International Journal of Modern Engineering Research, vol. 2, pp. 3927-3929, 2012.

10. K. Sreejith, "Experimental Investigation of A Domestic Refrigerator Having WaterCooled Condenser Using Various Compressor Oils," International Journal of Engineering and Science, Vols, vol. 2, pp. 27-31, 2013.

11. T. Mohd Yusof and A. A. Azizuddin, "Performance Analysis Of A Domestic Refrigerator," 2010.

12. K. Atik and A. Aktas, "An experimental investigation of the effect of refrigerant charge level on an automotive air conditioning system," Journal of Thermal Science and Technology, vol. 31, pp. 11-17, 2011.

13. J. H. Kim, J. M. Cho, I. H. Lee, J. S. Lee, and M. S. Kim, "Circulation concentration of $\mathrm{CO} 2$ propane mixtures and the effect of their charge on the cooling performance in an air-conditioning system," International Journal of Refrigeration, vol. 30, pp. 43-49, 1// 2007. 